\title{
How to enhance and assess reflection in specialist training: a mixed method validation study of a new tool for global assessment of reflection ability
}

\author{
Gunver Lillevang ${ }^{1}$, Helle Ibsen ${ }^{2^{*}} \mathbb{D}$, Søren Hast Prins ${ }^{3}$ and Niels Kristian Kjaer ${ }^{2}$
}

\begin{abstract}
Background: In Danish GP training we had the ambition to enhance and assess global reflection ability, but since we found no appropriate validated method in the literature, we decided to develop a new assessment tool. This tool is based on individual trainee developed mind maps and structured trainer-trainee discussions related to specific complex competencies. We named the tool Global Assessment of Reflection ability (GAR) and conducted a mixed method validation study. Our goal was to investigate whether it is possible to enhance and assess reflection ability using the tool.

Methods: In order to investigate acceptability, feasibility, face validity, and construct validity of the tool we conducted a mixed method validation study that combined 1) qualitative data obtained from 750 GP trainers participating in train-the-trainer courses, 2) a questionnaire survey sent to 349 GP trainers and 214 GP trainees and 3) a thorough analysis of eight trainer-trainee discussions.

Results: Our study showed an immediate high acceptance of the GAR tool. Both trainers and trainees found the tool feasible, useful, and relevant with acceptable face validity. Rating of eight audio recordings showed that the tool can demonstrate reflection during assessment of complex competencies.

Conclusions: We have developed an assessment tool (GAR) to enhance and assess reflection. GAR was found to be acceptable, feasible, relevant and with good face- and construct validity. GAR seems to be able to enhance the trainees' ability to reflect and provide a good basis for assessment in relation to complex competencies.
\end{abstract}

Keywords: Educational assessment, Reflection, Medical postgraduate education, General practice

\section{Background}

Clinical practice is never simple and straight forward. Doctors are practicing complex competencies in a clinical world embedded with uncertainty and where textbook knowledge only provides some of the answers

\footnotetext{
* Correspondence: heibsen@health.sdu.dk

${ }^{2}$ The Research Unit of General Practice, Department of Public Health, Faculty of Health Sciences, University of Southern Denmark, Campusvej 55, 5230 Odense M, Denmark

Full list of author information is available at the end of the article
}

$[1,2]$. Clinical decision making therefore requires that doctors can combine experience-based knowledge with evidence-based knowledge and that doctors can constructively process all kinds of formal and informal feedback [3]. Furthermore in a clinical setting inherited with complexity, uncertainty, and time constraint, the doctors often have to shift between analytical and non-analytical decision making [3]. The non-analytical clinical decision making is efficient but also error prone due to decision biases [4-6]. The only way to compensate these decision

C C The Author(s). 2020 Open Access This article is licensed under a Creative Commons Attribution 4.0 International License, which permits use, sharing, adaptation, distribution and reproduction in any medium or format, as long as you give appropriate credit to the original author(s) and the source, provide a link to the Creative Commons licence, and indicate if changes were made. The images or other third party material in this article are included in the article's Creative Commons licence, unless indicated otherwise in a credit line to the material. If material is not included in the article's Creative Commons licence and your intended use is not permitted by statutory regulation or exceeds the permitted use, you will need to obtain permission directly from the copyright holder. To view a copy of this licence, visit http://creativecommons.org/licenses/by/4.0/. The Creative Commons Public Domain Dedication waiver (http://creativecommons.org/publicdomain/zero/1.0/) applies to the data made available in this article, unless otherwise stated in a credit line to the data. 
biases is through deliberate reflection [5, 7]. Hence, doctors' ability to reflect is crucial for clinical practice and should therefore be addressed in medical education. Yet the concept "reflection" is not unequivocally defined in medical literature, and when we start to discuss how to teach reflection or even to assess it, ambiguities are mounting up $[8,9]$.

An ability to reflect is not only necessary for efficient use of feedback in medical education [10], it is also essential for clinical practice, and it has been argued that the ability to reflect on one's own role and performance is a key factor in reliable selfassessment and expertise development [11]. It therefore seems logical to teach and assess reflection in specialist training [12, 13].

Such a reflection ability, however, easily becomes an objective beyond the measurable $[8,9]$.

Traditional assessment methods face problems in assessing the complex clinical competencies that doctors are expected to handle $[14,15]$. In such complex competencies the ability to self-assess and reflect is a crucial part but trainee doctors may experience insufficient attempts to measure reflection as counterproductive or even harmful [16]. Since assessment of complex competencies is difficult, authors have suggested to shift focus from traditional summative assessment towards a more formative feedback and how to support learning [15].. Furthermore despite the challenge to assess reflection, it is well established that medical education benefits from training that aims to enhance the reflective capacity of the trainees [12].

A qualified attempt to measure reflection during medical training has been made by the Dutch authors Aukes et al. who developed a tool to measure self-reported level of reflection. They concluded that their tool only measures part of the reflection ability [17]. Other approaches to assessing written reflection have been suggested, e.g. REFLEC [18], and they show positive effects and possibilities in assessing reflection [19]. In continuing medical development collaborative reflection based on verbal exchange of thoughts and experiences has a long and strong tradition [20] and educational beneficial outcomes have been reported [2]. Based on the above-mentioned experiences we therefore assume that reflection ability can be enhanced and assessed by a combination of written reflections and verbal dialogue between trainer and trainee.

Realizing that exact measurement of reflection is impossible, but at same time respecting the importance of the concept, we have tried to develop a new workplacebased procedure, or tool, to enhance and assess reflection through systematic trainer-trainee discussions. We have named this tool "Global Assessment of Reflection ability" (GAR).
In order to validate the tool, we conducted a study in three parts addressing three research questions:

- Is GAR acceptable?

- What is the feasibility and face validity of GAR?

- What is the construct validity of GAR, i.e. does it assess the intended construct of reflection?

\section{Methods}

The development of the assessment tool was based on an understanding of reflection in line with the definition presented by the AMEE guide 44:" Reflection is a metacognitive process that creates a greater understanding of both the self and the situation so that future actions can be informed by this understanding. Self-regulated and lifelong learning have reflection as an essential aspect, and it is also required to develop both a therapeutic relationship and professional expertise." [12].

The tool is primarily focusing on formative assessment for further learning but also provides decision support for a summative yes/no assessment of the ability to reflect in relation to a specific complex competency. This is in line with a modern approach to assessment in medical education in which assessment is focused on the learning of trainees and at the same time used to "support trainers in taking entrustment decisions by contemplating their "gut-feeling" with information from assessments" [21].

\section{Description of GAR}

The GAR tool includes two phases.

1) Preparation: The trainee produces a mind map or similar written presentation in a concept formation process addressing a specific, complex competency. The trainee is given 1-2 weeks for the preparation and uses the description of the competency in the curriculum and possible portfolio notes as inspiration.

2) Structured discussion: The trainee gives a brief presentation of his/her mind map/written presentation. This serves as the basis for a structured discussion between trainer and trainee. The discussion includes references to knowledge and experiences that the trainee has obtained in relation to the assessed competency.

During the discussion the trainer assesses the following:

- Does the trainee show ability to reflect on the problem/competency and on his/her own role as a GP? 
- Does the trainee demonstrate relevant analytical skills concerning the problem/competency?

- Is the trainee able to participate open minded in a dialogue and demonstrate relevant flexibility?

The focus of the discussion is on formative aspects leading to a plan for further learning, but it also provides decision support for the trainers' summative pass or fail assessment of a specific competency.

The tool was introduced in the Danish general practice (GP) specialist training in 2014. In several of the complex competencies in the Danish Curriculum the GAR is an integrated part of the global assessment. These are competencies where the ability to reflect is crucial for mastering the competency. An example of a complex competency and a corresponding mind map is showed in appendix 1.

We conducted a study in three parts addressing three research questions:

\section{Acceptability}

The first part of the study addressed the acceptability of the tool. 750 GP trainers from two of Denmark's five regions (The Region of Southern Denmark and Region Zealand) were introduced to the tool on tutor courses during 2014 and 2015 as part of the nationwide implementation of a new GP curriculum. At the end of each of the in total 32 courses the participants were systematically asked "What do you think of the reflection tool?". All answers were written down by the teachers, analysed using systematic text analysis, and condensed into main categories of statements [22].

\section{Feasibility and face validity}

The second part of the study addressed feasibility and face validity of the tool.

A questionnaire survey was conducted among GP trainees and GP trainers, who were supposed to have used the new tool in real life because they had had a trainee after the implementation of GAR in the training programme.

Based on the results of the first part of the study we developed a questionnaire containing 12 closed questions regarding demographics, practical conditions, usefulness, and relevance of the tool. One open-ended question collected general views concerning GAR. The questionnaire could be answered within $5 \mathrm{~min}$.

The questionnaire was pilot tested for understandability and content validity in a think-aloud process by three GP trainees and three GP trainers [23]. No significant changes were made after the pilot. The questionnaire can be seen in Appendix 2.

The answers to the open-ended question were condensed and analysed using Systematic Text
Condensation [22] and summarized in three categories: Positive comments regarding GAR, negative comments regarding GAR, and comments concerning workload and general reluctance against schedules and mandatory learning and assessment methods.

In 2015 the questionnaire was sent by email to the 354 GP trainers and 216 GP trainees from The Region of Southern Denmark and Region Zealand, who were supposed to have used the tool in real-life clinical setting. Reminders were sent after 2 weeks. 5 GPs and 2 trainees were no longer working as GP trainers or GP trainees and were excluded from the study.

\section{Construct validity}

The third part of the study addressed the construct validity of the tool. We investigated whether relevant reflection was demonstrated by the GP trainees during authentic structured discussions using GAR.

In order to base our analysis and rating on an operational understanding of reflection, we chose to use the SOLO (Structure of Observed Learning Outcomes) taxonomy (Biggs and Collis 1982). This taxonomy operates with five levels of understanding; 1) pre-structural, 2) uni-structural, 3) multi-structural, 4) relational, 5) extended abstract [24]. Level 4 and 5 describe an understanding where different elements are integrated and conceptualized. We defined level 4 and 5 as reflection.

A multi-professional team of six educational experts developed and validated rating schemes applying the SOLO taxonomy onto two of the complex competencies to be assessed by GAR in the Danish GP specialist training programme.

We translated the five levels of the SOLO taxonomy into Danish. Then we split each of the two competencies into five observable objectives. The two rating schemes were constructed combining the descriptions of the SOLO levels $1-5$, the five observable objectives, and a global rating for each of the competencies. We scored the highest obtained SOLO level that was reached concerning each objective (Appendix 3). If some of the objectives were not addressed in the discussion no rating would be given.

The two rating schemes were piloted in a process where three experienced researchers each rated two authentic audio recorded structured discussions. The researchers discussed face-, content- and construct validity and found the rating schemes reliable and fit for purpose. An inter-rater variation analysis showed only few and minor differences in rating.

To obtain audio recorded authentic structured discussions for our study we had educational coordinators throughout Denmark repeatedly asking all relevant GP trainers and trainees to send their recorded discussions to the researchers, audiotaped via smartphone and sent 
by mail. This was done over the course of 1 year. The two rating schemes were used by two researchers to rate the authentic structured discussions. The two researchers rated independently and afterwards negotiated an agreement to reach the final rating of the discussions.

\section{Statistics}

Descriptive statistics and kappa inter-rater variability analysis was calculated in STATA 16.0.

\section{Results}

\section{Acceptability}

In the part of the study addressing acceptability we condensed the answers from the GP trainers into the following statements: "The tool makes good sense", "The tool seems to be feasible", "The tool is assumed to be a way to improve quality of trainer-trainee discussions", and "The tool is a way to obtain an understanding of the trainee's ability to reflect". Only one of the 750 trainers expressed negative views finding the instrument to be "waste of time and unnecessary".

Quotations: "GAR can make the trainee reflect on own practice", "The mind-map is useful in structured feedback when it comes to complex competencies".

\section{Feasibility and face validity}

In the questionnaire survey addressing feasibility and face validity we received a total of 301 responses, a response rate of $58 \%(201 / 349)$ for GP trainers and $47 \%$ $(100 / 214)$ for GP trainees. The majority of the respondents were female $(56 \%(112 / 201)$ of GP trainers and $78 \%(78 / 100)$ of GP trainees). The GP trainers' average age was 52 years. The trainees' average age was 31 years. We have no demographic data about non-responders.

$88 \%(264 / 301)$ of the trainers and trainees reported to be familiar with GAR, 37\% (110/301) had used the tool in vivo. 79\% (50/63) of the GP trainers and $72 \%(34 / 47)$ of the GP trainees who had used GAR found it useful or very useful. 81\% (51/63) of the GP trainers and 64\% (30/ 47) of the trainees who had used GAR found it relevant or very relevant (Table 1$)$.

The majority of the GP trainers $(73 \%(46 / 63))$ used less than $20 \mathrm{~min}$ for preparation before the structured discussion. $68 \%(32 / 47)$ of the trainees used less than 30 min for preparation. $74 \%(81 / 110)$ of the structured discussions were completed in $30 \mathrm{~min}$ or less.

The open-ended question in the survey was answered by $19 \%$ of the respondents $(57 / 301)$. Of these $42 \%$ gave positive statements regarding the tool, $17 \%$ gave negative statements regarding the tool and 40\% gave general statements in relation to education or other issues.
Table 1 Questionnaire survey

\begin{tabular}{lll}
\hline Usefulness and relevance & GP Trainers (63) & GP Trainees (47) \\
\hline Very useful & $19 \%(12 / 63)$ & $19 \%(9 / 47)$ \\
Useful & $60 \%(38 / 63)$ & $53 \%(25 / 47)$ \\
Less useful & $11 \%(7 / 63)$ & $19 \%(9 / 47)$ \\
Not Useful & $5 \%(3 / 63)$ & $2 \%(1 / 47)$ \\
Do not know & $5 \%(3 / 63)$ & $6 \%(3 / 47)$ \\
Very relevant & $17 \%(11 / 63)$ & $11 \%(5 / 47)$ \\
Relevant & $63 \%(40 / 63)$ & $53 \%(25 / 47)$ \\
Less relevant & $10 \%(6 / 63)$ & $21 \%(10 / 47)$ \\
Not relevant & $3 \%(2 / 63)$ & $9 \%(4 / 47)$ \\
Do not now & $6 \%(4 / 63)$ & $6 \%(3 / 47)$ \\
\hline
\end{tabular}

Responder's view of GAR's usefulness and relevance as at tool for assessing reflection

The condensed positive statements expressed the following opinions: "GAR stimulates reflection and formative assessment that strengthens professional development and in-depth understanding". "It is relevant for some complex competencies and helps the trainers to generate explicit language about issues that previously have been assessed only by implicit impressions". "The tool is suitable for strengthening the competent trainee but also suitable to help the trainer when in doubt about the summative assessment i.e. pass-fail decision".

The condensed negative statements expressed the following opinions: "The tool aims at measuring the unmeasurable and is trying to plan things that can't be planned". "It is time consuming and a waste of time". "Unstructured assessment without mandatory tools is preferred".

The condensed general statements expressed the following opinions: "Mandatory use minimizes motivation for using new learning or assessment methods". "New demands concerning education combined with high work-load in general practice gives less room for implementing new methods". Requests for less control in education were stated from both trainers and trainees.

\section{Construct validity}

Eight authentic structured discussions were rated according to the developed rating schemes. Kappa interrater agreement analysis showed 83\% agreement (Kappa 0.70 , SE $0,14, p<0.001$ ). This indicates a high degree of agreement. The two researchers negotiated and reached an agreement of the final rating (Table 2).

The mean global rating was 4,6 on the 5 -point scale based on the SOLO taxonomy, meaning that the 8 structured discussions on average ranked between what is called "relational" and "extended abstract" in the SOLO taxonomy which resembles our defined level of reflection. 
Table 2 Audio ratings

\begin{tabular}{|c|c|c|c|c|c|c|}
\hline Recording & $\begin{array}{l}\text { Item } 1 \\
\text { Patient } \\
\text { Encounter }{ }^{1}\end{array}$ & $\begin{array}{l}\text { Item } 2 \\
\text { Patient } \\
\text { encounter }{ }^{1}\end{array}$ & $\begin{array}{l}\text { Item } 3 \\
\text { Patient encounter }{ }^{1}\end{array}$ & $\begin{array}{l}\text { Item } 4 \\
\text { Patient } \\
\text { encounter }{ }^{1}\end{array}$ & $\begin{array}{l}\text { Item } 5 \\
\text { Patient encounter }{ }^{1}\end{array}$ & Global rating \\
\hline Trainee1 & 5 & 5 & 4 & $\mathrm{n} / \mathrm{a}$ & 5 & 5 \\
\hline \multirow[t]{2}{*}{ Trainee 2} & 4 & $\mathrm{n} / \mathrm{a}$ & 3 & $\mathrm{n} / \mathrm{a}$ & 4 & 4 \\
\hline & $\begin{array}{l}\text { Item } 1 \\
\text { Educator }^{2}\end{array}$ & $\begin{array}{l}\text { Item } 2 \\
\text { Educator }^{2}\end{array}$ & $\begin{array}{l}\text { Item } 3 \\
\text { Educator }^{2}\end{array}$ & $\begin{array}{l}\text { Item } 4 \\
\text { Educator }\end{array}$ & $\begin{array}{l}\text { Item } 5 \\
\text { Educator }^{2}\end{array}$ & Global rating \\
\hline Trainee 3 & 4 & 5 & 5 & $\mathrm{n} / \mathrm{a}$ & 5 & 5 \\
\hline Trainee 4 & 4 & 5 & 5 & 5 & 5 & 5 \\
\hline Trainee 5 & 5 & 5 & 4 & 5 & 5 & 5 \\
\hline Trainee 6 & 4 & 5 & 5 & 5 & 5 & 5 \\
\hline Trainee 7 & 4 & 3 & 3 & 3 & 4 & 3 \\
\hline Trainee 8 & $\mathrm{n} / \mathrm{a}$ & $\mathrm{n} / \mathrm{a}$ & 5 & 5 & 5 & 5 \\
\hline Mean & & & & & & 4.6 \\
\hline
\end{tabular}

Rating of the 8 audio recordings of real-life assessments according to the SOLO taxonomy

$1=$ pre-structural, $2=$ uni-structural, $3=$ multi-structural, $4=$ relational, $5=$ extended abstract (ref). Level 4 and 5 defined as reflection

$\mathrm{n} / \mathrm{a}=$ not rated

1) Trainee 1-2. Competency: "Different types of patient encounters" which includes the ability to use the different kinds of patient encounters (consultation, home visit, telephone call etc.) adequately and embrace individual, social, cultural and contextual considerations

2) Trainee 3-8. Competency: "Educator" including skills for teaching colleagues and staff considering aspects of target group, prior qualifications, and factors enhancing or inhibiting learning

\section{Discussion}

\section{Principal findings}

Our study shows an initial high acceptance to the introduction of GAR among Danish GP trainers. However, the responses in the following survey were more diverse.

The feasibility and face validity of GAR seems high among the trainees and trainers who have used the tool. Both GP trainers and trainees found the tool useful and relevant. The trainers and trainees reported that the tool stimulates reflection in relation to complex competencies and helps trainers assess complex competencies by generating explicit language about matters previously only informed by implicit impressions. Compared to the prior situation with only implicit and intuitive judgment the tool seems to be suitable for strengthening the competent trainee. However, the implementation of the tool as part of the daily work-based assessment is proceeding at a relatively slow pace. We also found some general resistance against structured educational initiatives among both trainers and trainees and GAR was met with skepticism by some, because of time constraints in busy clinical settings and a reluctance due to an impression of rising demands of control in the society.

Ratings of the audio recordings showed an acceptable inter-rater variability and it demonstrated reflection in the trainer-trainee discussions concerning complex competencies.

We conclude that GAR has a sufficient degree of construct validity, i.e. that appropriate assessment of the trainee's ability to reflect can be made using the tool.

Our tool was seen by most trainers and trainees as acceptable, feasible, and having face and construct validity
- characteristics that are essential for success in assessment in medical education [25]. In another Danish study GAR was found to be less used than the other assessment methods in the specialist training programme, but was found similarly valuable by those who used it [26].

Some trainers and trainees were skeptical towards GAR. We know from other studies that some resistance can be expected from experienced clinicians presented with attempts to map uncertainty, or potential educationally reductive approaches to complex competencies [2, 14].

We find this a relevant reservation, which should be considered when improving our reflection tool. Nevertheless the relevance of attempts to enhance and assess the ability to reflect is well supported by literature [12].

Attempts to support reflective thinking in specialist training is not new. Written clinical incidences via an online portfolio have been used in Denmark since 2004 and has been proven beneficial for some but not all trainees [27]. In our study, however, we have focused on assessing verbal trainer-trainee discussions with a formative focus based on a prior mind-mapping and concept formation process where the trainee creates a written presentation. The literature supports the use of mindmaps and trainer-trainee discussions to enhance reflection [28]. Reflection-driven development is also seen in verbally founded reflective learning groups $[2,20]$. In expertise development theories the ability to reflect is prerequisite for competence development and support our educational focus on reflection $[29,30]$.

We think these findings support our attempt to enhance and assess reflection in medical education. 


\section{Strengths and weaknesses}

In the acceptability part of the study we invited 760 of ordinary trainers to test the tool in vitro at our trainthe-trainer courses. The trainers came from two different parts of the country having participated in different trainer courses with different instructors.

In spite of time constraints and the reported in-born skepticism towards new assessment methods, the vast majority found the tool acceptable. However, the result was based on initial experiences obtained in a training session and answers given verbally, which might influence the response.

To investigate feasibility and face validity, we asked ordinary trainers and trainees via a questionnaire survey to evaluate the tool after having tried it in their own practices in authentic settings. We invited both GP trainers and trainees to participate in the survey to engage both perspectives and we invited participants from two different educational regions to avoid bias according to personal or regional issues. The response rate was acceptable both for GP trainers and trainees.

In the survey based on GP trainers and trainees after a single non-guided first-time use, we would expect difficulties and resistance, but we found a high degree of perceived usefulness and relevance among the users of the tool. However, a substantial number of participants had not yet used the tool at the time of the survey which enhances the risk of selection bias.

Investigating construct validity, one would often test against a golden standard. We did not have a golden standard to test our tool against, though, and we had to find another approach. We found that the SOLO taxonomy could help us rate reflection as intended. Unfortunately, we have not found literature using the same method in assessing reflection in a clinical setting to support our findings. However, earlier researchers have shown other possible approaches to assess written reflections supporting learning, indicating that clinical reflection can be assessed [17, 19, 27].

We hypothesized that reflection can be graduated into levels from superficial to deep critical reflection and chose the recognized SOLO taxonomy to rate the level of reflection in the trainer-trainee discussions. The rating scheme was thoroughly elaborated by six professionals with different educational background, four physicians, an educationalist, and a psychologist.

We obtained an acceptable degree of inter-rater agreement using the rating schemes. However, we experienced practical difficulties collecting recorded, authentic structured discussions. We had to repeat the invitation to record just to reach the number of 8 recordings, which is quite a small amount of material. We assume the technical challenge in busy daily GP practice combined with some professional shyness account for some of the recruitment difficulties. Therefore, there is undoubtedly a degree of selection bias in our study. But even with our limited material the tool demonstrated measurable reflection in relation to complex competencies.

\section{Implications and further research}

We assume that the GAR tool could be relevant to apply in other settings than Danish GP training, but larger scale studies are needed to detect level of obtained reflection and the tool's ability to discriminate among high and low performers in different professional sociocultural settings. It also needs to be explored whether a tool such as GAR will stimulate more demonstrated reflection than an unstructured but engaged trainertrainee discussion.

\section{Conclusions}

We have developed an assessment tool (GAR) to enhance and assess reflection. GAR was found to be acceptable, feasible, and relevant by most trainers and trainees. The study indicated that both face- and construct validity is good. GAR seems to be able to enhance the trainees' ability to reflect and provide a good basis for assessment in relation to complex competencies.

\section{Appendix 1}

Table 3 Competency \# 8: Teaching. From the Danish curriculum for GP specialist training. Translated from Danish by the authors

\begin{tabular}{|c|c|c|}
\hline Description & $\begin{array}{l}\text { Learning } \\
\text { strategy }\end{array}$ & Assessment \\
\hline $\begin{array}{l}\text { The doctor must be able to: } \\
\text { Teach colleagues, staff, and } \\
\text { non-health educated } \\
\text { persons. } \\
\text { Communicate professional } \\
\text { topics while taking the } \\
\text { recipient's background into } \\
\text { account. } \\
\text { In a constructive way apply } \\
\text { knowledge of factors that } \\
\text { can promote learning in } \\
\text { the clinic and demonstrate } \\
\text { awareness of factors that } \\
\text { may inhibit learning. } \\
\text { Demonstrate awareness of } \\
\text { the fact that the patient - } \\
\text { when taking part in } \\
\text { teaching - can be both the } \\
\text { teacher and the learner. } \\
\text { Role: Scholar }\end{array}$ & $\begin{array}{l}\text { Participation in } \\
\text { internal } \\
\text { teaching in } \\
\text { clinic. } \\
\text { Participation in } \\
\text { specialty training } \\
\text { courses. }\end{array}$ & $\begin{array}{l}\text { Assessment by Global } \\
\text { assessment of reflection } \\
\text { ability (GAR) }\end{array}$ \\
\hline
\end{tabular}




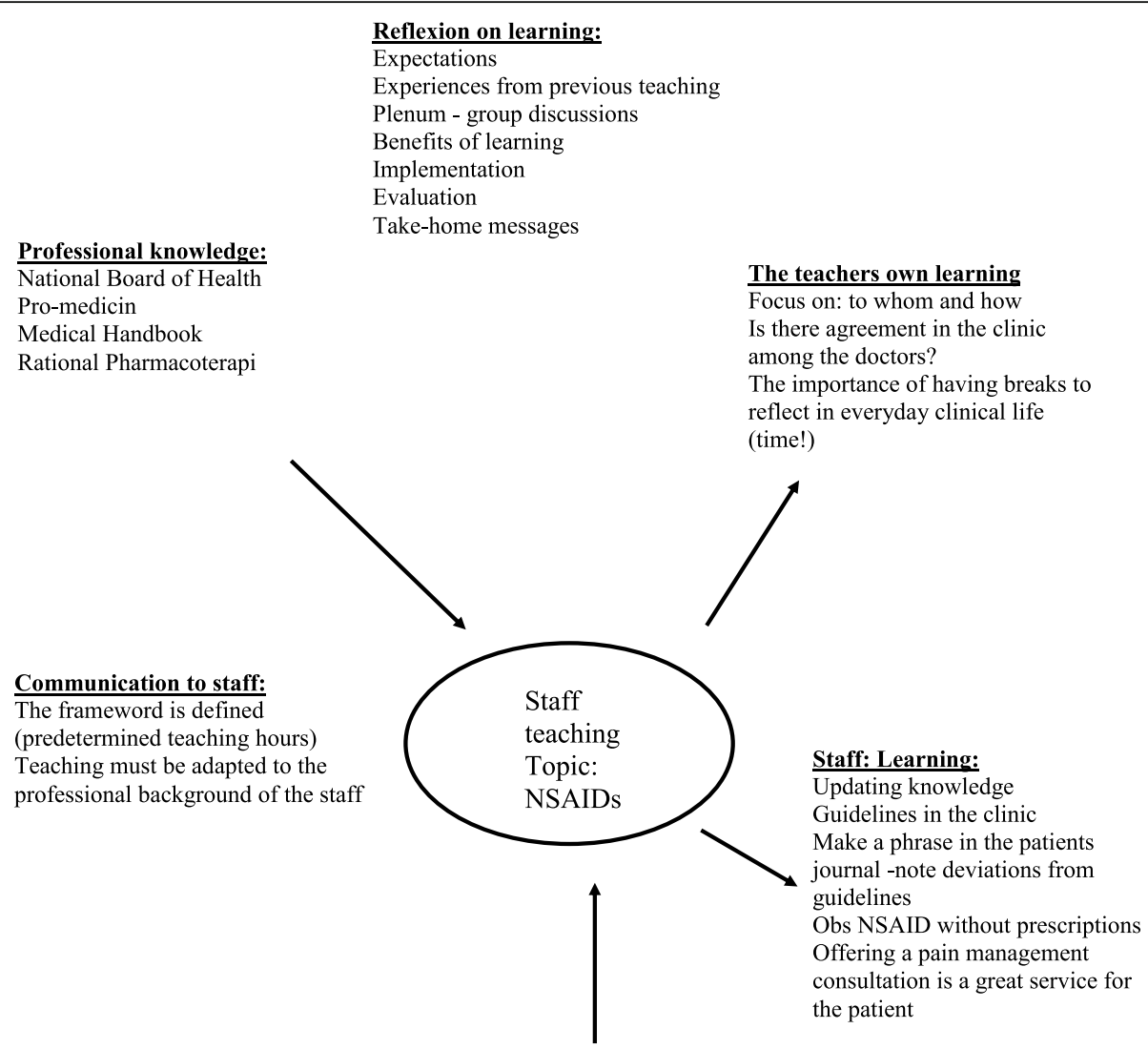

\section{Choise of topic}

- Problems that cause difficulties for staff or

- Areas where new knowledge need to be implemented

Motivation:

Relevant for staff

Usable/useful in the daily work

in the clinic

Fig. 1 Example of a corresponding mind map. Mind-map published with accept from the participants

\section{Appendix 2 Electronic questionnaire}

\section{What is your position?}

Trainer

Trainee in introductory year

Trainee in specialist training

Other (please specify)

2. What is your gender?

Woman

Man

3 . What is your age?

$<25$ years

25 - 35 years

$36-45$ years
$46-55$ years

$56-65$ years

$>65$ years

4. Do you know the Global Assessment of Reflection ability tool (GAR)?

Yes, and I have used GAR

Yes, but I have not yet used GAR

No, I do not know GAR

Other (please specify)

5. How did you and your trainer/trainee prepare before using GAR?

The trainer prepared in advance

The trainee prepared in advance 
Both the trainer and trainee prepared in advance We used GAR without preparation

We have not used GAR

6. How long time have you spent preparing for GAR? (If you have used GAR more than once please indicate the average time for preparation)

Less than 10 minutes

10 - 20 minutes

21 - 30 minutes

31 - 40 minutes

41 - 50 minutes

51 - 60 minutes

More than 60 minutes 25

I have not prepared for GAR

Other (please specify)

7. How long time have you spent on the structured discussion as part of GAR with your trainer/trainee? (If you have used GAR more than once please indicate the average time)

Under 10 minutes

10 - 20 minutes

21 - 30 minutes

31 - 40 minutes

41 - 50 minutes

51 - 60 minutes

More than 60 minutes

We have not had a GAR structured discussion, please state reason:

8. How do you rate the usefulness of GAR as a tool for assessing the ability of a trainee to reflect?

Very useful

Useful

Not so useful

Not useful at all

Do not know

Have not used GAR
9. ONLY FOR TRAINEES: Have you used the guiding questions and mind map examples for trainees regarding GAR? (see the guiding questions and mind maps examples via the link below) http:// www.dsam.dk/flx/courses/student/competencevaluation/guide_conferences_of_requirement/)

Yes, and the questions/mind map examples were helpful

Yes, but the questions and mind map examples were not as helpful as I had hoped for

No, I did not need the questions or mind map examples

No, I was not aware of the questions and mind map examples

Other (please specify)

10. ONLY FOR TRAINERS: Have you used the assessment criteria for trainers regarding GAR? (See the assessment criteria via the link below) http:// www.dsam.dk/flx/uddannelse/fremuddannelse_i almen_medicin/kompetencevurdering/vejlederssamtale_vurdering_af_refleksionsevne/)

Yes, and the assessment criteria were helpful

Yes, but the assessment criteria were not as helpful as I had hoped for

No, I did not need the assessment criteria

No, I was not aware of the assessment criteria 26

Other (please specify)

11. How do you rate the relevance of GAR as a method for assessing reflection?

Very relevant

Relevant

Not so relevant

Not relevant at all

Do not know

Have not used GAR

12. If you have any comments on GAR, suggestions for application, experience with the application or anything else you are welcome to write this here: 


\section{Appendix 3}

Table 4 Rating scheme for structured discussions

$\begin{array}{lll}\text { QUANTITATIVE } & & \text { QUALITATIVE } \\ \text { SOLO } 2 & \text { SOLO } 3 & \text { SOLO } 4\end{array}$

Ability to reflect on topical issue and one's own work, role and options.

Educator

Considerations about prior qualifications, level, and needs in the target group

Considerations about adaptation to prior qualifications, level, and needs in the target group

Considerations about teaching method(s)

Considerations about factors enhancing and inhibiting learning

Considerations about own work, role and options in relation to teaching colleagues and staff

Global rating

\section{Different types of patient encounters}

Memorise, identify, recognise, count, define, find label, match, name, quote, recall recite, order, tell, write imitate
"Multi-structural"

"Relational"

Classify, describe, list, report, discuss, recognise, count, define, find label, match, name, quote, recall recite, order, tell, write imitate illustrate, select, narrate, compute, sequence, outline, separate
Apply, integrate analyse, explain, predict, conclude, summarise, review, argue, transfer, make a plan, characterise, compare, contrast, differentiate, organise, debate, make a case, construct, review and rewrite, examine, translate, paraphrase, solve a problem
SOLO 5

"Extended abstract"

Theorise, hypothesise, generalise, reflect, generate, create, compose, invent, originate, prove from first principles, make an original case, solve from first principles
Classify, describe, list, Apply, integrate analyse, explain, predict, conclude, summarise, review, argue, transfer, make a plan, characterise, compare, contrast, differentiate, organise, debate, make a case, construct, review and rewrite, examine, translate, paraphrase, solve a problem narrate, comp sequence, outline, separate
Theorise, hypothesise, generalise, reflect, generate, create, compose, invent, originate, prove from first

Considerations about implications for patient communication in different kinds of patient encounters (consultation, phone calls, email, home visits)

Considerations about own role in relation to home visits

Considerations about impact of individual, societal, cultural, and contextual circumstances in relation to patient communication and presentation of symptoms

Considerations about patient communication using an interpreter

Considerations about impact on communication in case of interruptions, need for prioritising several simultaneous 
Table 4 Rating scheme for structured discussions (Continued)

tasks, communication about

several topics at a time, and

communication with numerous

persons at a time

Global rating

\section{Abbreviations}

GAR: Global assessment of reflection; GP: General practice

\section{Acknowledgements}

The authors wish to thank Charlotte Søjnæs, and Birgitte Dahl Pedersen for their contribution to the development of the rating schemes based on the SOLO taxonomy,

Thanks to Jonas Halfdan Ry Hessler for participating in the pilot testing of the rating schemes.

Thanks to Søren Olsson and Ingeborg Netterstrømt for taking part in the early design phase of the study.

\section{Authors' contributions}

$G L$ has taken part in all steps of the study from protocol to article. HI has participated in data collection in parts 1,2 and 3. SHP has taken part in validation and data collection in part 3. NKK has taken part in data analysis. All authors have actively taken part in writing the article. The author (s) read and approved the final manuscript.

\section{Funding}

The study was partly funded by the Danish GP education and development fund.

\section{Availability of data and materials}

The datasets used and/or analysed during the current study are available from the corresponding author on reasonable request. However, the recorded trainer/trainee conversations are confidential and are therefore not available.

\section{Ethics approval and consent to participate}

According to Danish regulations, the study did not need formal approval from a health research ethics committee. The study complies with the World Medical Association Declaration of Helsinki, including providing informed consent to study participation: All participants in the questionnaire study gave consent by active participation. All participants in the audiotaped structured discussions gave verbally informed consent to participation and publication of anonymised results. The informed consent was given verbally according to Danish regulations and was noted by the researchers. https:// www retsinformation.dk/Forms/R0710.aspx?id=201254.

The National Committee on Health Ethics in Denmark has been consulted and according to Danish law, this type of study needed no further approval from the committee. The research ethics committee at SDU was started in late 2018 and only provides approvals for projects initiated subsequently. Hence, we have strictly followed all regulations pertinent to our study.

\section{Consent for publication}

Not applicable.

\section{Competing interests}

The authors declare that they have no competing interests.

\section{Author details}

${ }^{1}$ Department of Clinical Medicine, University of Copenhagen, Blegdamsvej 3B, 2200 Copenhagen N, Denmark. ${ }^{2}$ The Research Unit of General Practice, Department of Public Health, Faculty of Health Sciences, University of Southern Denmark, Campusvej 55, 5230 Odense M, Denmark. ${ }^{3}$ Centre for Health Sciences Education, Health, Aarhus University, Palle Juul-Jensens Boulevard 82, 8200 Aarhus N, Denmark.
Received: 19 April 2020 Accepted: 24 September 2020

Published online: 08 October 2020

\section{References}

1. Schön D. The reflective practitioner. How professionals think in action. United Kingdom: Ashgate/Arena, Aldershot; 1983.

2. Kjaer NK, Stolberg B, Coles C. Collaborative engagement with colleagues may provide better care for 'heart-sink' patients. Educ Prim Care. 2015;26(4): 233-9.

3. Norman G, Young M, Brooks L. Non-analytical models of clinical reasoning: the role of experience. Med Educ. 2007:41(12):1140-5.

4. Mamede S, Schmidt HG, Rikers R. Diagnostic errors and reflective practice in medicine. J Eval Clin Pract. 2007:13(1):138-45.

5. Mamede S, Splinter TA, van Gog T, Rikers RM, Schmidt HG. Exploring the role of salient distracting clinical features in the emergence of diagnostic errors and the mechanisms through which reflection counteracts mistakes. BMJ Qual Saf. 2012:21(4):295-300.

6. Norman GR, Eva KW. Diagnostic error and clinical reasoning. Med Educ. 2010:44(1):94-100

7. van den Berge K, Mamede S. Cognitive diagnostic error in internal medicine. Eur J Intern Med. 2013;24(6):525-9.

8. Koole S, Dornan T, Aper L, Scherpbier A, Valcke M, Cohen-Schotanus J, Derese A. Factors confounding the assessment of reflection: a critical review. BMC Med Educ. 2011:11:104.

9. de la Croix A, Veen $M$. The reflective zombie: problematizing the conceptual framework of reflection in medical education. Perspect Med Educ. 2018;7(6): 394-400.

10. Mamede S, van Gog T, Sampaio AM, de Faria RM, Maria JP, Schmidt HG How can students' diagnostic competence benefit most from practice with clinical cases? The effects of structured reflection on future diagnosis of the same and novel diseases. Acad Med. 2014;89(1):121-7.

11. Ericsson KA. Deliberate practice and acquisition of expert performance: a general overview. Acad Emerg Med. 2008;15(11):988-94.

12. Sandars J. The use of reflection in medical education: AMEE guide no. 44. Med Teach. 2009:31(8):685-95.

13. Ribeiro LMC, Mamede S, de Brito EM, Moura AS, de Faria RMD, Schmidt HG. Effects of deliberate reflection on students' engagement in learning and learning outcomes. Med Educ. 2019;53(4):390-7.

14. Talbot M. Monkey see, monkey do: a critique of the competency model in graduate medical education. Med Educ. 2004;38(6):587-92.

15. Brightwell A, Grant J. Competency-based training: who benefits? Postgrad Med J. 2013;89(1048):107-10. https://doi.org/10.1136/postgradmedj-2012130881. Epub 2012 Sep 27.

16. Murdoch-Eaton D, Sandars J. Reflection: moving from a mandatory ritual to meaningful professional development. Arch Dis Child. 2014;99(3):279-83.

17. Aukes LC, Geertsma J, Cohen-Schotanus J, Zwierstra RP, Slaets JP. The development of a scale to measure personal reflection in medical practice and education. Med Teach. 2007;29(2-3):177-82.

18. Wald HS, Borkan JM, Taylor JS, Anthony D, Reis SP. Fostering and evaluating reflective capacity in medical education: developing the REFLECT rubric for assessing reflective writing. Acad Med. 2012;87(1):41-50.

19. Driessen EW, van Tartwijk J, Overeem K, Vermunt JD, van der Vleuten CP. Conditions for successful reflective use of portfolios in undergraduate medical education. Med Educ. 2005;39(12):1230-5.

20. Pinder R, McKee A, Sackin P, Salinsky J, Samuel O, Suckling H. Talking about my patient: the Balint approach in GP education. Occas Pap R Coll Gen Pract. 2006:87:1-32.

21. Driessen $\mathrm{E}$, Scheele F. What is wrong with assessment in postgraduate training? Lessons from clinical practice and educational research. Med Teach. 2013;35(7):569-74.

22. Malterud K. Systematic text condensation: a strategy for qualitative analysis. Scand J Public Health. 2012;40(8):795-805. 
23. Olsen H: (Guide to good qustionnaires) In Danish Socialforskninginstituttet, Denmark; 2006.

24. Biggs J, Collis K. Evaluating the quality of learning: the SOLO taxonomy. New York: Academic press; 1982.

25. Norcini J, Anderson B, Bollela V, Burch V, Costa MJ, Duvivier R, Gallbraith R, Hays R, Kent A, Perrott V, et al. Criteria for good assessment: consensus statement and recommendations from the Ottawa 2010 conference. Med Teach. 2011;33(3):206-14.

26. Prins SH, Brondt SG, Malling B. Implementation of workplace-based assessment in general practice. Educ Prim Care. 2019;30(3):133-44.

27. Kjaer NK, Maagaard R, Wied S. Using an online portfolio in postgraduate training. Med Teach. 2006;28(8):708-12.

28. Zanting A, Verloop N, Vermunt JD. Using interviews and concept maps to access mentor teachers' practical knowledge. High Educ. 2003;46(2): 195-214.

29. Ericsson KA. Deliberate practice and the acquisition and maintenance of expert performance in medicine and related domains. Acad Med. 2004; 79(10 Suppl):S70-81.

30. Schmidt HG, Rikers RM. How expertise develops in medicine: knowledge encapsulation and illness script formation. Med Educ. 2007;41(12):1133-9.

\section{Publisher's Note}

Springer Nature remains neutral with regard to jurisdictional claims in published maps and institutional affiliations.

Ready to submit your research? Choose BMC and benefit from:

- fast, convenient online submission

- thorough peer review by experienced researchers in your field

- rapid publication on acceptance

- support for research data, including large and complex data types

- gold Open Access which fosters wider collaboration and increased citations

- maximum visibility for your research: over $100 \mathrm{M}$ website views per year

At BMC, research is always in progress.

Learn more biomedcentral.com/submissions 